\title{
A propaganda oral radiofônica enquanto gênero textual: implicações argumentativas e referenciais
}

\section{The oral merchandising on the radio as a textual genre: argumentative and referential implications}

\author{
Maria Francisca Oliveira Santos ${ }^{1}$
}

DOI: $10.28998 / 2317-9945.2019 n 63 p 37-46$

\section{Resumo}

Os estudos argumentativos da linguagem propiciam a leitura, análise e compreensão do sentido em gêneros, com destaque para os estudos da referenciação, em que objetos de discurso, por serem construidos e reconstruidos na mente dos interlocutores e nas relações sociais, permitem a acessibilidade ao sentido nos mais diversos gêneros. A referenciação é voltada à maneira de introdução de novos elementos em um texto, bem como ações de retomadas por meio de recategorizações manifestadas e não manifestadas lexicalmente no texto. Assim, este trabalho objetiva analisar o gênero textual spot a partir da Linguística Textual, numa perspectiva sociocognitivo-discursiva, tomando o texto como processo, lugar de interação, estabelecendo um diálogo entre elementos argumentativos, com categorias orais e referenciais, considerando como se dá o tecer sociocognitivo do gênero em estudo, permitindo a efetividade dos aspectos argumentativos e referenciais no citado gênero, veiculado em linha radiofônica. A metodologia percorrida é de linha qualitativa com uma análise descritivo-interpretativa, e a pesquisa é realizada com as informações em processo e, tendo como referencial teórico os trabalhos de: Cavalcante, Custódio Filho e Brito (2014), Koch (2004), Fiorin (2015). Os resultados apontam para uma construção no jogo interativo do texto, por meio de pistas argumentativas e referenciais que favorecem a produção do sentido textual.

Palavras-chave: Argumentação. Referenciação. Gênero textual spot

\begin{abstract}
The argumentative studies of language provide the reading, analysis and understanding of meaning in genres, with emphasis on reference studies, in which objects of discourse, being constructed and reconstructed in the minds of interlocutors and in social relations, allow the access to meaning in different genres. The reference is focused on the way of introducing new elements in a text, as well as actions of reiteration through recategorisations manifested and not manifested lexically in the text. Thus, this work aims to analyze the textual genre spot, based on Textual Linguistics, in a socio-cognitive-discursive perspective, seeing the text as a process, place of interaction, establishing a dialogue between argumentative elements, oral and referential categories, taking into consideration how the socio-cognitive dimension of the studied genre works, allowing the effectiveness of the argumentative and referential aspects in the aforementioned genre which is broadcasted via radio. The methodology employed in this study was the qualitative research with a descriptiveinterpretative analysis and it was developed using the information in process, based on the following theoretical framework: Cavalcante, Custódio Filho and Brito (2014), Koch (2004), Fiorin (2015). The results point to a construction in the interactive game of the text, through argumentative and referential cues that contribute to the production of textual meaning.
\end{abstract}

Keywords: Argumentation. Reference. Textual genre spot

Recebido em: 11/01/2019.

Aceito em: 17/03/2019.

\footnotetext{
1 Doutora em Linguística pela Universidade Federal de Pernambuco. Professora do Programa de Pósgraduação em Linguística e Literatura da Universidade Federal de Alagoas e da Universidade Estadual de Alagoas. Líder do grupo de pesquisa "Linguagem e Retórica" (CNPq/Uneal).
} 


\section{Considerações iniciais}

Este trabalho se insere nos estudos da Linguística Textual, que tem como objeto de análise o texto, considerado o lugar da interação entre atores sociais e, obviamente, da construção interacional de sentidos $(\mathrm{KOCH}, 2004)$, enquadrando-se na concepção de base sociocognitiva-interacional, embora essa concepção se imbrique com a comunicacional, a pragmática, dentre outras. Afirma-se, ainda, tal como Weedwood (2002), que se trata de uma macrolinguística, envolvida com a função social das línguas, considerando-se as relações dessa língua com as situações contextuais.

Essa área do conhecimento (Linguística Textual) também se desenvolve com uma concepção de língua correspondente, "uma atividade que permite a construção do conhecimento e convivência entre os seres" (SILVEIRA, 1999, p. 50), realizando-se num espaço interativo de construção (espaço radiofônico) dos atores sociais, responsáveis de maneira intersubjetiva pelo processo comunicativo da linguagem.

Assim, língua, texto, atores sociais e sentidos textuais são sinteticamente entendidos, neste trabalho como: língua entendida como interação, sujeitos como construtores do sentido, tendo o texto como próprio lugar interativo; atores sociais entendidos como aqueles que, numa maneira interativa, são construídos e passam pelo processo construtivo; e, enfim, o sentido dos textos, elementos também construídos na interação entre texto e sujeitos.

O texto em análise é do gênero spot, na modalidade de língua oral, considerando-se as especificidades da oralidade, que Ingedore Koch aponta, em seus estudos, para diferenças típicas entre fala e escrita, como, por exemplo: a primeira é contextualizada; a segunda, descontextualizada; atualmente, assegura-se: "fala e escrita apresentam tipos de complexidade diferentes" (KOCH, 2003, p. 78). Assim, no presente estudo, o texto oral configura-se no gênero propaganda, de caráter midiático, numa interlocução constante entre interlocutor (locutor) e ouvintes (rádio do interior do agreste), sendo os gêneros entendidos como: "[...] formas de conhecimento cultural que emolduram e medeiam conceitualmente a maneira como entendemos e agimos tipicamente em diversas situações" (BAWARSHI; REIFF, 2013, p. 16).

No campo da argumentação, em suas linhas iniciais, Ducrot (1972) propõe a introdução de um componente retórico no que for destinado aos estudos da linguagem, que responda pelo sentido do enunciado em uso (numa situação de comunicação), ao tempo em que era proposto também um componente linguístico, responsável pelo sentido atribuído à proposição na língua. Depois, Anscombre e Ducrot (1997) privilegiam a noção de argumentação que se distancia da de discursivização. Nesse momento, postula-se uma pragmática integrada, ou seja, é a pragmática indissociável da semântica. Para Fiorin (2015, p. 16), "o componente retórico não é algo que se acrescenta ao componente semântico, mas ele faz parte deste componente". Para essa pragmática integrada, entende-se por argumentação "o encadeamento dos enunciados que conduz a certa conclusão, seu domínio preferencial é o estudo dos conectores que realizam esse encadeamento" (FIORIN, 2015, p. 17), acrescentando-se a isso, têm-se a orientação argumentativa que se dá aos enunciados e os topoi, explicados pelos encadeamentos operados na área da superfície pelos conectores.

Assim, operando as análises, as teorias do discurso não se limitam a uma microanálise linguística, mas, muitas vezes, delas fazem uso para a conversa com a exterioridade. Dessa forma, para Fiorin (2015, p. 17), "as teorias do discurso devem levar 
em conta dois aspectos: de um lado, a organização das unidades discursivas transfrásticas; de outro, o modo de funcionamento real do discurso, ou seja, seu caráter dialógico”.

O trabalho em foco sustenta-se na linha sociodiscursiva dos estudos da linguagem, aceitando a interação entre a rádio (locutor) e o auditório social (ouvintes), por meio de textos, concretizados em gêneros, na modalidade oral, os quais variam de acordo com o contexto em que esses atores sociais estão interagindo. Cada situação de linguagem pode determinar qual gênero é mais bem apropriado àquele momento, àquela situação; acontecendo também de maneira vice-versa. A escolha de um gênero dentre os que existem na tipologia do narrar, argumentar, descrever, dentre outras, acontece pelo conhecimento pré-existente que se tem em si e também na própria sociedade, havendo modelos prédeterminados a serem apropriados e adequados à nova ação linguística.

Por isso, na linha argumentativa, tem-se uma proposta em que o gênero textual, em sua modalidade oral, propicia que os atores sociais argumentem entre si numa ação sociocognitiva, por meio dos seus mecanismos referenciais. Nesse sentido, é a referenciação a retomada de elementos para a construção do sentido textual. Argumentativamente, elementos referenciais no gênero spot permitem a circulação e construção dos sentidos entre os atores sociais.

A referenciação apresenta características fundamentais, pois a linguagem pode prover o acesso a uma realidade do mundo; permitir a negociação dos sentidos veiculados nos gêneros apresentados em textos orais ou escritos; e estabelecer a junção entre o processo de conhecer e as experiências culturais (processo sociocognitivo). Nesse sentido, a referenciação é uma "proposta teórica que salienta o caráter altamente dinâmico do processo de construção dos referentes em um texto" (CAVALCANTE; CUSTÓDIO FILHO; BRITO, 2014, p. 7).

Atenta-se ainda para o valor da coerência textual, do conhecimento de mundo e interacional, bem como para os processos de referenciação. A propaganda, gênero textual midiático, apresenta elementos referenciais, os "objetos-de-discurso", os quais circulam na sua esfera específica, requerendo espaço interpretativo na memória do ouvinte (rádio), a fim de que os sentidos sejam construídos, e o objetivo da mensagem (compra do produto remédio) atinja o público-alvo específico.

É importante acrescentar que o corpus foi coletado a partir de CDs gravados, com duração de duas horas consecutivas de um programa de rádio em determinada emissora, localizada no agreste alagoano. Foram retirados, aleatoriamente, 2 spots para análise à luz dos aspectos argumentativos provindos da Oralidade e da Referenciação.

Diante disso, no primeiro momento é realizada uma discussão acerca dos objetos de discurso, procurando entender como eles (re)constroem os sentidos do texto. Em seguida, há a discussão entre os aspectos orais e referenciais do gênero spot, evidenciando como eles estão imbricados no referido gênero. Por fim, tem-se as análises e as considerações finais.

\section{Acerca dos objetos de discurso}

Entre as categorias de acesso ao sentido apontadas, está a coesão, voltada ao estudo da referência que tem elementos da língua como itens "que não podem ser interpretados semanticamente por si mesmos, mas remetem a outros itens do discurso necessários à sua 
interpretação" (KOCH, 2003, p. 19), de caráter endofórico e exofórico, conforme o referente esteja dentro ou fora do texto, respectivamente. Assim, a identificação de elos coesivos se dava simplesmente pela remissão de formas remissivas, de forma anafórica ou catafórica, a um ou mais constituintes do universo textual, sendo essas formas consideradas "objetos-do-mundo"; para isso, não se evidenciavam os valores sociocognitivos, ligados a aspectos contextuais do evento de fala enunciado.

Diferentemente da posição apontada, este trabalho segue Koch (2004), além de Apothéloz e Rechler-Béguelin (1995) e Mondada e Dubois (1995), para os quais a referência significa tudo que é designado e representado quando se usa um termo ou mesmo quando é criada uma situação discursiva referencial que tenha essa finalidade. Assim, as entidades designadas pelos referentes são chamadas objetos-de-discurso, que constituem "um conjunto de informações inclusas no saber compartilhado pelos interlocutores" (LIMA, 2007, p. 81), ou ainda dizendo "é a representação na mente dos interlocutores de uma entidade estabelecida no texto (CAVALCANTE; CUSTÓDIO FILHO; BRITO, 2014, p. 27).

No gênero em análise, o spot, sempre aparecem, pela primeira vez, referentes, que possibilitam a sequenciação dos fazeres argumentativos nele introduzidos. Isso constitui a chamada introdução referencial, que acontece "quando um referente ou objeto de discurso 'estreia' no texto de alguma maneira, sendo possível por meio de expressão referencial" (CAVALCANTE; CUSTÓDIO FILHO; BRITO, 2014, p. 54) que é a estrutura da língua utilizada para manifestar formalmente, no chamado contexto, a representação que se faz do referente. Assim, em tomar Vita Clin (exemplo 1), os últimos termos (Vita Clin) constituem as expressões referenciais, sendo os objetos-de-discurso enunciados em situações contextuais diferentes como: precisamos usar o remédio (Vita Clin); anunciamos que esse remédio é de todo mundo Vita Clin e, finalmente, devemos comprar o produto Vita Clin.

Exemplo 1:

“... precisamos tomar Vita Clin... Vita Clin... a vitamina da gente ... vá na farmácia mais próxima de ... vá na farmácia mais próxima de sua casa e compre Vita Clin...”

Considerando que a coerência está ligada aos sentidos depreendidos por locutor e ouvinte, num processo interlocutivo, em consonância com os conhecimentos ativados e com a adequação entre esses conhecimentos e o universo cognitivo pertencente a esses atores comunicativos, a falta de coerência poderá acontecer se os textos não forem apropriados a determinadas situações (KOCH; TRAVAGLIA, 1998, p. 32). Para esses autores, existem fatores que propiciam a coerência, como os elementos linguísticos, $\mathrm{O}$ conhecimento de mundo e os elementos pragmáticos e interacionais, o que pode ser evidenciado no exemplo 2:

Exemplo 2:

"esta vida moderna é FOGO... acordar cedo... preparar o café para o marido...levar as crianças na escola... UFA..."

O fragmento da propaganda torna-se compreensível e assimilado por ouvintes da Rádio Novo Nordeste por apresentar cadeia linguística intelegivel (entende-se o que significa a vida moderna, vida de muito trabalho), as informações veiculadas (ações que constituem uma vida de trabalho); e as razões por que foi construída a propagada em estudo. 
Pela importância atribuída, neste trabalho, a aspectos da oralidade e da referenciação, com foco na recategorização metafórica, volta-se para esses itens sem que sejam postos de lado os anteriores, pois fazem parte da constituição do universo teórico e sociocognitivo que permeia o trabalho.

\section{Aspectos argumentativos: caracteres orais e referenciais}

Conforme dito anteriormente, o gênero spot apresenta idiossincrasias, exemplificadas pelo envolvimento dos papéis dos interlocutores, pela execução das ações e, ainda, pela elaboração e construção do próprio texto. Assim, o citado gênero aparece numa linguagem informal, dirigido a qualquer tipo de ouvinte, o especializado ou não, tendo a finalidade de a mensagem ser logo apreendida, como a compra do medicamento indicado, Vita Clin.

As marcas da oralidade aparecem representadas pelas pausas como em: "cabeça aos pés...", “os ossos..."; "nervos fracos...", "desânimo e cansaço...”, entre outros exemplos; pelas entonações enfáticas: "O FORTIFICANTE DO TRABALHADOR, UM GRANDE TRABALHADOR"; aliteração, que se dá pela repetição da mesma palavra no início de cada juízo de valor acerca do referencial "Tiogenol"; pelos paralelismos sintático e semântico: "Tiogenol fortalece você da cabeça aos pés"; "Tiogenol fortalece os ossos... combate casos de nervos fracos... desânimo e cansaço... contra dores do corpo... estresses... esgotamento físico... /... tome Tiogenol...”

Por se tratar de um gênero midiático em que o locutor se dirige a um suposto ouvinte das mais diferentes classes sociais, acontece permanecer sozinho no turno, podendo surgir a ideia de uma relação assimétrica; no entanto, se forem observadas as astúcias desse locutor para transformar seu texto interativo, portanto, de fácil acesso ao ouvinte, entende-se que seja esse gênero mesclado por circuitos entonacionais que permitem a sua circulação entre a natureza simétrica e assimétrica.

Quanto aos aspectos relacionados à referenciação, evidencia-se ser ela de muita importância para a produção-compreensão de sentidos, tendo uma dimensão discursiva. Ela caracteriza-se como uma "proposta teórica que salienta o caráter altamente dinâmico do processo de construção dos referentes em um texto" (CAVALCANTE; CUSTÓDIO FILHO; BRITO, 2014, p. 7).

A referenciação no gênero spot acontece pela anáfora direta ou correferencial (retomada de um referente por meio de uma nova expressão referencial), pela repetição, uma vez que a expressão referencial se repete, e pelo hiperônimo, uma vez que ações vêm em ascendência da menor à maior. Os excertos mostram a evidência da referenciação:

Exemplo 3:

"vá na farmácia mais próxima de sua casa e compre Vita Clin..."

O exemplo mostra uma anáfora direta, pois "sua casa" faz uma continuidade de sentidos, referindo-se ao mesmo locutor por outra expressão.

Exemplo 4:

"mais do que nunca precisamos tomar Vita Clin... Vita Clin... a vitamina da gente... vá na farmácia 
mais próxima de sua casa e compre Vita Clin..." referencial.

Evidencia-se, no exemplo 4, a correferencialidade pela repetição do introdutor

Além da anáfora, aparece o fenômeno da dêixis, representada pelo conjunto de palavras, ou mesmo expressões, que apresentam como principal papel "apontar" para o conteúdo situacional. "Diferentemente dos anafóricos, os dêiticos se definem por sua capacidade de criar um vínculo entre o contexto e a situação enunciativa em que se encontram os participantes da comunicação" (CAVALCANTE; CUSTÓDIO FILHO; BRITO, 2014, p. 85). Assim, tem-se a dêixis de pessoa, de tempo e de espaço, que só é entendida se "o interlocutor souber algumas coordenadas do enunciador: quem fala, para quem fala, de onde fala e quanto fala" (CAVALCANTE, 2013, p. 128). Os exemplos a seguir mostram:

Exemplo 5:

“... a noite estamos um bagaço... mais do que nunca precisamos tomar Vita Clin... agora estou com um fogo que só vendo...”

O exemplo 5 mostra uma dêixis representada pela categoria de pessoa, envolvendo todas as mulheres, isso demonstrado pelo uso da forma verbal, "estamos", no plural, que engloba todas as mulheres em geral, para, depois, em um passo imaginativo de ações dos atores sociais (radialista e ouvinte), restringir-se à primeira pessoa, quando se diz: "agora estou com um fogo que só vendo...”. Já no exemplo a seguir, destaca-se o dêitico espacial, como se vê:

Exemplo 6:

... vá na farmácia mais próxima de sua casa e compre Vita Clin...

O exemplo 6 mostra a dêixis espacial, pois é preciso que se conheça o contexto sociocognitivo da propaganda para imaginar que se trata de uma localização de farmácia próxima do local da residência do ouvinte. Ainda exemplificada, aparece a dêixis temporal, quando expressões dêiticas, exemplificadas por sintagmas adverbiais como "agora", "ontem"; ou mesmo, por grupo de ações que codificam o tempo em relação ao momento da comunicação, como no exemplo a seguir:

Exemplo 7:

"acordar cedo... preparar o café para o marido... levar as crianças na escola... UFA... quanto trabalho... à noite estamos um bagaço",

Essa sequência das ações faz com que o ouvinte tenha uma enumeração delas, considerando a linha temporal da sua realização.

A referenciação ainda é contemplada, neste trabalho, com o olhar na anáfora encapsuladora, que apresenta como principal característica resumir porções contextuais, tendo nessa situação a soma de outros dados de conhecimentos partilhados. É o encapsulamento uma estratégia que vai auxiliar no desenvolvimento da capacidade de o ouvinte captar o texto que se encerra ou se amplia, de acordo com as expressões comunicativas. Nesse sentido, Cavalcante, Custódio Filho e Brito (2014) assim enunciam: 
O mecanismo de encapsulamento, portanto, é uma das estratégias para prover um 'resumo' textual de diferentes extensões. Tanto pode dar conta de trechos menores como de porções maiores. Saber quando utilizá-lo e ser capaz de fazer a escolha linguística adequada são habilidades importantes a serem desenvolvidas nos alunos (CAVALCANTE; CUSTÓDIO FILHO; BRITO, 2014, p. 84).

Para Custódio Filho (2012), nos estudos da referenciação são visualizadas duas tendências específicas, sendo a primeira caracterizada por abranger trabalhos que propõem um quadro geral das estratégias referenciais, nele incluídos os trabalhos de Koch e Marcuschi (1998), Koch (2003) e Cavalcante (2003). São estudos que tratam de estratégias no tocante à referenciação específica, como a anáfora recategorizadora, a indireta, o encapsulamento e o estudo da dêixis.

Diferentemente, os postulados da segunda linha da referenciação não estão centrados em olhar a anáfora nos moldes da relação identificatória entre sintagmas nominais no texto, mas parte-se dos usos, investigando quais fatores agem contextualmente para a construção do sentido. Preenchem essa perspectiva os trabalhos baseados na "possibilidade de uma expressão referencial retomar um objeto de discurso presente em outro cotexto, o que fala em favor de uma anáfora intertextual" (COSTA, 2007), dentre outros.

Prosseguindo nessa linha, Lima (2007) aponta recategorizações manifestadas e não manifestadas lexicalmente, conforme sejam explicadas por anáforas correferenciais, explicitadas por metáforas, havendo busca de elementos contextuais para depreensão do sentido nas relações comunicativas. De outra forma, não aparecem sinais correferenciais, sendo o sentido depreendido pela busca de outros fatores como o conhecimento de mundo e do contexto da comunicação, fora do universo cotextual. Na primeira perspectiva (recategorização manifestada pela metáfora), aparece o exemplo 8 a seguir:

Exemplo 8:

esta vida moderna é FOGO... acordar cedo... preparar o café para o marido... levar as crianças na escola... UFA... quanto trabalho... à noite estamos um bagaço... mais do que nunca precisamos tomar Vita Clin... quando o maridão chega nem parece que eu trabalhei tanto... agora estou com um FOGO que só vendo...

O exemplo 8 exibe um falante, que trata da lida feminina (radialista), ao enunciar ser a vida atual "fogo", de muito trabalho, justificando isso com as expressões “... preparar o café para o marido... levar as crianças na escola... UFA... quanto trabalho... à noite estamos um bagaço...”. Depois de todas essas ações, trabalhando a memória sociocognitiva dos ouvintes, fazendo reter e conferir com a realidade vivenciada (conhecimento de mundo) por cada parceiro da comunicação, é enunciado: “... agora estou com um FOGO que só vendo...”, para apelar para a sensibilidade sexual da mulher, para daí ela chegar a tomar o remédio.

Os aspectos argumentativos, num misto da oralidade e da referenciação, permitem uma melhor análise do gênero midiático propaganda oral $(s p o t)$, mostrando, de um lado categorias como pausas, hesitações, entonações, turnos, dentre outras especificidades e, de outro, aquelas como as anáforas, especificamente os encapsulamentos, dentre outros elementos referendados, para a construção dos sentidos em gêneros textuais. 


\section{O gênero spot à luz da análise}

O trabalho insere-se numa abordagem qualitativa, uma vez que se volta ao estudo da aquisição do saber em processo e não na sua obtenção como produto. É uma linha de estudo que "requer que os investigadores desenvolvam empatia para com as pessoas que fazem parte do estudo e que façam esforços concentrados para compreender vários pontos de vista" (BOGDAN; BIKLEN, 1994, p. 287).

O corpus foi coletado a partir de CDs gravados, com duração de duas horas consecutivas de um programa de rádio em determinada emissora, localizada no agreste alagoano. Foram retirados, aleatoriamente, 2 spots para análise à luz dos aspectos argumentativos provindos da oralidade e da referenciação. As transcrições foram feitas, seguindo as normas propostas por Marcuschi (1986) e Preti (1998).

O spot a seguir (amostragem 1) trata da divulgação do medicamento Vita Clin, mostrando a sua composição (A...B1...B2...B6...B12...PP...C...D e E...), bem como a sua ação como "fortificante energético".

esta vida moderna é FOGO... acordar cedo... preparar o café para o marido...levar as crianças na escola... UFA... quanto trabalho... à noite estamos um bagaço... mais do que nunca precisamos tomar Vita Clin... é um fortificante energético com vitaminas A...B1...B2...B6...B12...PP...C...D e E... quando o maridão chega nem parece que eu trabalhei tanto... agora estou com um fogo que só vendo...Vita Clin... a vitamina da gente... vá na farmácia mais próxima de sua casa e compre Vita Clin...

O gênero apontado revela as lamúrias de mulheres em sua labuta diária, evidenciando suas opiniões como: "acordar cedo... preparar o café para o marido... levar as crianças na escola... UFA", e a vida é caracterizada por uma grande metáfora fogo, constituindo o que fora dito um conjunto de ações que justificam o uso do hiperônimo, partindo de fogo a bagaço, em: "à noite estamos um bagaço". Como não fosse suficiente, num trabalho perspicaz com o ouvinte, o radialista procura fazer a mente feminina, criando imagens de devaneio, ao usar a recategorização lexical em ... "agora estou com um fogo que só vendo...", em que fogo = desejo sexual.

A propaganda tem especificidades da língua falada, tendo sido enunciada em um único turno, de caráter assimétrico, conversando com um suposto ouvinte, procurando persuadi-lo para aquisição do Vita Clin. Assim, aparecem: a) pausas "FOGO... acordar cedo"; b) repetição propriamente dita: Vita Clin .Vita Clin e Vita Clin; paralelismo sintático e semântico - "vá na farmácia mais próxima de sua casa e compre Vita Clin..."; entonação enfática: UFA.

O radialista retoma a imagem de dona de casa, ao afirmar: "quando o maridão chega nem parece que eu trabalhei tanto", momento quando convida o ouvinte para ouvir a assertiva, mostrando sua identidade à ideia "Vita Clin... a vitamina da gente", solicitando conhecimentos por parte do ouvinte acerca do que enuncia, propiciando um jogo interativo entre as imagens criadas na mente do seu ouvinte e as do falante.

Num jogo interativo entre ideias, falante e ouvinte, partilhando o que há de melhor de seu conhecimento de mundo, finaliza-se a propaganda assim: "vá na farmácia mais próxima de sua casa e compre Vita Clin...", em que a dêixis espacial faz um aconselhamento em relação à aquisição do remédio. 


\section{Considerações finais}

Os estudos textuais percorrem a evolução dos tempos, seguindo as influências sociais vivenciadas pela humanidade. Isso é o que justifica a evolução conceitual do que se entende por texto, contemplado antes por especificações como frase completa, signo complexo, discurso congelado, operações mentais, até a assimilação atual de lugar de interação onde convergem ações de interlocutores numa situação sociodiscursiva. Desse modo, foi possível perceber que o falante (radialista) procura estabelecer o sentido das ideias que passa por meio da propaganda oral para fazer com que, revestido na figura feminina, possa persuadir os ouvintes que escutam a rádio a comprar o remédio indicado.

O texto analisado na concepção sociodiscursiva efetiva-se no gênero textual propaganda, na modalidade oral, cujas especificidades construtivas estão ligadas a pausas, hesitações, truncamentos, dentre outras especificidades orais, cuja função no processo de entendimento textual é a efetivação da coerência textual, que, certamente, no gênero em estudo, é concretizada também porque os elementos referenciais, "os objetos-de-discurso", elementos pulsantes no processo de sentido do texto, impulsionam a referenciação pelo acesso à realidade (informações acerca do Vita Clin), pela natureza sociocognitiva da linguagem (as passagens mentais operadas pela ação dos referentes) e, sobretudo, pela negociação (permissão para que os referentes sejam configurados).

$\mathrm{Na}$ cadeia da referenciação, o gênero propaganda oral destacou não somente a anáfora direta correferenciada, a dêixis e o hiperônimo (menção de um sentido amplo ao menor), mas também as anáforas encapsuladoras, pois comumente exercem funções argumentatvas que são decisivas "[...] para o projeto de dizer de cada enunciador, no momento em que buscam o melhor modo de designar, de sintetizar parafraseando um ponto de vista (e, consequentemente, rebatendo outros, ditos ou não)" (CAVALCANTE; CUSTÓDIO FILHO; BRITO, 2014, p. 80). Assim, o encapsulamento no gênero propaganda, que começa com o referente fogo em "esta vida moderna é FOGO..." em que fogo aparece com um sentido metafórico, significando vida de trabalho, passa, quando encapsulada em outro fragmento como "... agora estou com um FOGO que só vendo..", ao tomar o remédio indicado, a mostrar todo o trabalho sociocognitivo inferido por esse processo referencial, o que confirmou o sentido negociado.

\section{Referências}

ANSCOMBRE, J. Claude; DUCROT, Oswald. L'argumentation dans la langue. Liège: Mardaga, 1997.

APOTHÉLOZ, D. ; REICHLER-BÉGUELIN, M. J. Construction de la référence et stratégies e désignation. In: BERRENDONNER, A. ; REICHLER-BÉGUELIN, M. J. (org.) Du sintagme nominal aux objets-de-discours. Neuchâtel: Université de Neuchâtel, 1995, p. 142-73.

BAWARSHI, Anis S.; REIFF, Mary Jo. Gênero: história, teoria, pesquisa, ensino. Trad. Benedito Gomes Bezerra. São Paulo: Parábola Editorial, 2013.

BOGDAN, Roberto C.; BIKLEN, Sari Knopp. Investigação qualitativa em educação. Trad. Maria João Alvarez, Sara Bahia dos Santos e Telmo Mourinho Baptista. Porto: Porto Editora, 1994. 
CAVALCANTE, Mônica Magalhães. Expressões referenciais - uma proposta classificatória. Caderno de Estudos Linguísticos, Campinas, v. 44, p. 105-118, jan./jun. 2003.

CAVALCANTE, Mônica Magalhães. Os sentidos do texto. São Paulo: Contexto, 2013.

CAVALCANTE, Mônica Magalhães; CUSTÓDIO FILHO, Valdinar; BRITO, Mariza Angélica Paiva. Coerência, referenciação e ensino. São Paulo: Cortez Editora, 2014.

COSTA, M. H. A. Acessibilidade de referentes: um convite à reflexão. 2007. Tese (Doutorado em Linguística) - Universidade Federal do Ceará, Fortaleza, 2007.

CÚSTÓDIO FILHO, Valdinar. Reflexões sobre a recategorização referencial sem menção anafórica. Linguagem em (Dis)curso, Tubarão/SC, v. 12, n. 3, p. 839-858, set./dez. 2012.

DUCROT, O. Dire et ne pas dire. Paris: Hermann, 1972.

FIORIN, José Luiz. Argumentação. São Paulo: Contexto, 2015.

KOCH, Ingedore; MARCUSCHI, L. A. Processos de referenciação na produção discursiva. D.E.L.T.A, v. 14, p. 169-190, 1998 (número especial).

KOCH, Ingedore; TRAVAGLIA. A coerência textual. 8 ed. São Paulo: Contexto, 1998.

KOCH, Ingedore. Desvendando os segredos do texto. São Paulo: Contexto, 2003.

KOCH, Ingedore. A coesão textual. 19 ed. São Paulo: Contexto, 2004.

LIMA, S. M. C. Recategorização metafórica e humor: uma proposta classificatória. In: CAVALCANTE, M. M. et al. (org.). Texto e discurso sob múltiplos olhares, v. 2: referenciação e outros domínios discursivos. Rio de Janeiro: Lucerna, 2007, p. 74-103.

MARCUSCHI, L. A. Análise da conversação. São Paulo: Ática, 1986.

MONDADA, Lorenza; DUBOIS, Danièle. Construction des objets de discours et categorisation: une approche des processus de référenciation. In: BERRENDONNER, A.; REICHLER-BEGUELIN, M-J. (org.). Du sintagme nominal aux objets-de-discours. Neuchâtel: Université de Neuchâtel, 1995, p. 273-302

SILVEIRA, Maria Inez Matoso. Línguas estrangeiras: uma visão histórica das abordagens, métodos e técnicas de ensino. Maceió: Edições Catavento, 1999.

WEEDWOOD, Barbara. História concisa da linguística. São Paulo: Parábola Editorial, 2002. 